\title{
A Transparência na Gestão Pública: Ferramenta Indispensável para Participação Social
}

\author{
Lêda Maria de Souza Santos ${ }^{1}$; Claudia Maria Lourenço da Silva ${ }^{2}$
}

\begin{abstract}
Resumo: Entender como ocorre o processo de transparência na gestão dos municípios, e os desafios e perspectivas que os gestores municipais têm frente a uma realidade social bem como a importância da mesma para as politicas públicas são os principais objetivos deste trabalho. A gestão de territórios é um desafio muito grande frente às demandas impostas pela sociedade na prestação de serviços essenciais necessários aos cidadãos, onde os recursos devem ser gastos de forma transparente e eficiente seguindo a legalidade e os demais princípios constitucionais previstos na Constituição Federal de 1988. Neste estudo abordaremos a pesquisa qualitativa de cunho bibliográfico que por meio do método dedutivo será feita uma analise e um estudo detalhado sobre algumas concepções e desafios e conceitos sobre a transparência na gestão pública. A partir das concepções de alguns autores foi possível embasar a parte teórica deste artigo.
\end{abstract}

Palavras Chave: Gestão, Democracia, Transparência.

\section{Transparency In Public Management: Vital Tool For Social Participation}

\begin{abstract}
Analyze how is the process of transparency in the management of municipalities, and the challenges and prospects that city managers have against a social reality and the importance of it to public policies are the main objectives of this work. territory management is a very big challenge facing the demands imposed by society in providing essential services required by citizens, where resources should be spent transparently and efficiently following the law and other constitutional principles provided for in the Federal Constitution of 1988. in this study we discuss the qualitative research literature nature that through the deductive method will be an analysis and a detailed study of some concepts and challenges and concepts of transparency in public management. From the views of some authors such as Freire (2006), the 1988 Federal Constitution, the Fiscal Responsibility Law (FRL) Bodart (2015) Courses (1990) O'Donnel (1976) will be possible to base the theoretical part of this article where our concern on the subject will allow an overview.
\end{abstract}

Keywords: Management, Democracy, Transparency.

\section{Introdução}

A gestão pública tem sido tema de estudo em todo âmbito na administração de territórios nacionais, pois possui características e exigências próprias para atender e

\footnotetext{
${ }^{1}$ Discente do curso de Pós-graduação (Lato Sensu)em Gestão Pública Municipal da Universidade Federal do Vale do São Francisco Univasf. E-mail: ledasvieira@hotmail.com

${ }^{2}$ Docente-orientadora do curso de Pós-graduação (Lato Sensu) em Gestão Pública Municipal da Universidade Federal do Vale do São Francisco - Univasf. Mestre em Gestão do Desenvolvimento Local Sustentável - FCAP/UPE e Doutoranda em Educação em Ciências UFRGS. E-mail: claudialourenco71@gmail.com
} 
contemplar a demanda social. Trata-se, portanto, de fortalecer procedimentos de participação da sociedade civil e nos processos de decisão e dividindo responsabilidades.

É necessário entender como ocorre o processo de transparência na gestão dos municípios, e os desafios e perspectivas que os gestores municipais têm frente a uma realidade social. Esses princípios devem estar atrelados às políticas públicas.

A presente pesquisa está relacionada com a universalidade da informação e publicidade de atos públicos referentes à gestão municipal. Neste sentido surge o questionamento. Como a transparência e vinculação da informação podem contribuir para uma gestão pública democrática alinhada as leis que regem a administração pública?

A Lei de responsabilidade fiscal diz que a transparência é um instrumento essencial no controle fiscal sendo assegurado pela participação da sociedade onde no artigo 37 traz princípios constitucionais que podem garantir a eficácia e eficiência da gestão pública.

Baseado nessa perspectiva, este trabalho que é de cunho bibliográfico, utilizou como base de pesquisa a abordagem qualitativa por meio do método dedutivo com leituras de textos para fundamentação teórica do tema obedecendo a uma estruturação em tópicos que irão conceituar analisar e esclarecer a inquietação da pesquisa. Neste sentido temos como destaca Trivíños (1971) As indicações propostas do sujeito, além de serem claras, precisas e expressas numa linguagem natural, adequada ao ambiente no qual se realiza a pesquisa, devem apontar os assuntos medidores do problema. Isso confirma a responsabilidade do pesquisador em deixar claro o que quer exatamente do seu entrevistado com as questões propostas. (TRVIÑOS, 1987, p. 171)

O princípio das ideias dos autores que serão citados ao longo de todo trabalho, irão contribuir para a análise em questão observando os princípios da Constituição Federal de 1988

\section{Gestão Pública e Democracia}

Este tópico visa investigar, apresentar e conceituar o conhecimento que se tem sobre democracia bem como sua relação com a gestão pública que se concretiza na vida de todos os cidadãos. 
Democracia é uma doutrina ou regime político baseado nos princípios da soberania popular e da distribuição equitativa do poder, ou seja, regime de governo que se caracteriza em essência pela liberdade do ato eleitoral, ela divisão dos poderes e pelo controle da autoridade. Gestão é o mesmo que gerir e esses significados estabelecem uma relação reciproca visto que na gestão no âmbito educacional é necessária a democracia para que o processo aconteça de maneira legal partindo dos principais princípios da gestão pública.

Alguns enfatizam que a democracia seja a participação nas decisões, outros destacando a importância da observância e fundamentação das leis, onde supõe, além da livre escolha dos governantes e representantes, das decisões por maiorias, a convivência e o diálogo entre pessoas que pensam de modos distintos e querem coisas distintas, mostra o reconhecimento da diversidade social e a superação das desigualdades sociais.

O aprendizado democrático implica na capacidade de discutir, elaborar e aceitar regras coletivamente, assim como a superação de obstáculos, por meio do diálogo, para a construção de propósitos comuns. Uma gestão democrática e participativa do poder público deve buscar, pelo diálogo e pela mobilização das pessoas, a participação nos princípios de convivência democrática que estabeleçam relações mútuas entre a Gestão e cidadãos.

De acordo Dagnino (2010), a democracia é condição necessária para construir um estado que promova o bem-estar da maioria. O processo democrático é fundamental para uma gestão eficaz. Governos quando trabalham ouvindo e vendo as necessidades dos munícipes fazem a democracia acontecer.

A democracia é ferramenta fundamental para gestão dos municípios sem a qual não temos uma gestão eficaz e neste sentido de acordo Dagnino (2008) sem democracia não existe participação social.

O processo de democratização política em nosso país foi caracterizado pela capacidade de mobilização dos setores da sociedade civil, que reivindicavam seu direito de participação política e nas tomada de decisões defendiam que a descentralização relacionarse-ia positivamente com democracia, eficiência e inovação na gestão pública.

A Constituição Federal de 1988 define a obrigatoriedade da adoção de espaços de participação em diversas áreas de políticas públicas. Assim, nas últimas décadas, temos o compartilhamento de experiências de democracia participativa nas esferas do governo. 
A participação consiste na voz, onde cidadãos podem buscar alternativas para um problema. A voz do povo tem um custo e isso implica numa negociação, tempo esclarecimentos sobre determinado problema. Neste sentido o entendimento sobre o crescimento do município depende da participação e mobilização de todos. Acreditamos que a participação é um processo interativo construído quando o povo se sente mobilizado para realizar algo de forma coletiva para a melhoria da qualidade de vida do município.

A Gestão pública e sua liderança devem estar atreladas a democracia uma vez que um governo eficaz precisa da participação em massa dos cidadãos que um ato democrático os colocou no poder para gerir de maneira eficiente os estados e municípios da federação. Em conformidade a isso temos:Uma liderança democrática durante seu tempo de vigência, porém, é mais estável que uma liderança totalitária, pois não há a necessidade de um inimigo externo nem a necessidade de promover expurgos sociais, em suma, não se alimenta ignorância e ódio para estabilizar a sociedade, daí deter o poder numa democracia é sempre melhor do que numa ditadura, pois não se tem o risco de um atentado ou um golpe a todo o momento. Isso vale para empresas ou sociedades econômicas, não no sentido da igualdade entre o dono do negócio e os contratados para operacionalizá-lo, mas no sentido de se ter uma regra clara de gestão, sem favoritismos, aplicados e princípios como a ascensão pelo mérito e resultados, uma vez que favoritismos sem fundamento objetivo via de regra fazem o negócio "afundar", em disputas de sócios, gestores e empregados, favorecendo pessoas que não possuem alcance intelectual, tirando do foco o objetivo social. (SILVA, 2010, p.16)

A administração pública deve estar amparada no princípio constitucional da eficiência e da legalidade e neste sentido Campos (1999) afirma que a administração pública é democraticamente eficiente quando algumas ações são tomadas, tais como, organização dos cidadãos para exercer o controle político do governo e participação social.

Acreditamos que o princípio da democracia fomenta a participação, a divulgação de informações, decisão coletiva que irão contribuir de maneira eficaz na construção de valores dando estabilidade ao gestor. 
Id on Line Revista Multidisciplinar e de Psicologia

Id on Line Multidisciplinary Journal and Psycology

\section{Transparência Pública: Elemento Essencial para Gestão dos Municípios e controle de fiscalização.}

A Constituição Federal de 1988 que se tornou conhecida como Constituição Cidadã traz no seu texto um capítulo que trata dos direitos sociais inerentes a toda população no Art. 194. A seguridade Social compreende um conjunto integrado de ações de iniciativa dos poderes públicos e da sociedade, destinada a assegurar os diretos à saúde, à previdência e à assistência social.

O princípio da sinceridade da gestão pública faz-se necessário uma vez que contempla as necessidades de a sociedade conhecer como foram utilizados os recursos que movimentam a máquina pública. Neste sentido uma boa gestão deve ser amparada por princípios regidos por leis e neste sentido.Regulamentada pela Lei Federal $n^{\circ}$ 8.666/93, que visa garantir fielmente o princípio constitucional da isonomia, a seleção da proposta mais vantajosa para a administração, seguindo os seguintes princípios: I. Princípios da Legalidade; II. Princípios da Impessoalidade; III. Princípios da Moralidade; IV. Princípios da Igualdade; V. Princípios da Publicidade; VI. Princípios da Probidade Administrativa; VII. Princípios da Vinculação ao Instrumento Convocatório; VIII. Princípios do Julgamento Objetivo e; IX. Princípios dos que lhe são Correlatados. (BODART, 2015, p.79)

A constituição Federal dispõe sobre os princípios legais que regem a administração pública onde a mesma deve ser transparente e em consonância ao artigo 37 sobre a gestão pública direta ou indireta temos no artigo 67 da LRF (Lei de Responsabilidade Fiscal) que é necessário a descentralização das práticas que resultem em maior eficácia e execução de gastos públicos observando a receita do município:

É importante salientar que a eficiência de uma entidade governamental não pode ser medida pelo aumento de suas receitas ou pela redução de seus gastos, mesmo que estes aspectos sejam importantes na atual situação financeira e orçamentária. Os melhores indicadores de eficiência, neste caso, são a qualidade e a intensidade com que tal entidade realiza os propósitos públicos. Julgar se o governo em termos de lucros e perdas, como se fosse uma empresa comercial, com a expectativa de que gaste pouco, não incorra em dividas e mantenha seu orçamento equilibrado, é um equívoco comum entre nós. Sem desconsiderar a necessidade da existência de certo equilíbrio entre o que se gasta com o que se pode arrecadar, 
a eficiência de um governo deve ser sempre julgada à luz de sua contribuição para a satisfação das necessidades e dos ideais do povo. (FORTUNATI, 2007, p. 21)

Amparada como princípio constitucional a eficiência é requisito obrigatório na transparência mostrando a situação financeira e orçamentaria dos municípios e neste sentido acreditamos que a mesma deve estar ligada a qualidade de serviços essenciais que devem ser oferecidos à população observando o planejamento e diretrizes estabelecidos por lei. Em conformidade Fortunati (2007) diz que a administração dos recursos públicos exige constantemente a cooperação de pessoas no planejamento na organização, na educação e na direção do próprio comportamento.

O Princípio da Legalidade está relacionado ao agir em conformidade com a Lei. O Princípio da Impessoalidade dispõe que as ações planejadas sejam para o bem-estar coletivo e com tratamento igualitário para todos, não fazendo autopromoção. (BODART, 2015, p.79)

Os princípios em que embasam a lei no que se refere à realização estimativa financeira concede ao cidadão o direito de acesso a todos os procedimentos que concretizam a aquisição ou prestação de serviços, desde o procedimento licitatório até o conhecimento do favorecido pelo pagamento.

O artigo 49 da Lei de Responsabilidade deixa claro que o executivo deve deixar a disposição à consulta da receita e despesas do município. Neste sentido é necessário expor num portal de transparência todas as informações sobre os investimentos e gastos do município. Cabe ao poder legislativo fiscalizar de forma eficaz tudo referente à receita e as despesas. O artigo 31 da Constituição Federal de 1988 diz que a fiscalização do Município será exercida pelo Poder Legislativo municipal, mediante controle externo, e pelos sistemas de controle interno do Poder Executivo municipal, na forma da lei. É necessário visitar os sites e portais de transparência do município a fim de verificar todos os processos de orçamento, participando da gestão administrativa, contribuindo para o desenvolvimento dos serviços prestados a toda população.

Segundo Fortunati (2007) a publicidade é requisito universal de um governo democrático. É a oportunidade de que o povo possui para conhecer e aquilatar as ações do governo.

Quando falamos na publicidade dos atos de um governo, não estamos nos referindo unicamente aos atos políticos, escrito senso, mas a todas as ações que dizem respeito aos 
Id on Line Revista Multidisciplinar e de Psicoloqia

Id on Line Multidisciplinary Journal and Psycology

interesses do cidadão. Desta forma, a publicidade e a divulgação ampla da peça orçamentária tornam-se uma obrigatoriedade indiscutível, pois moldam a intenção do referido governo para o próximo período e possibilitam ao cidadão tecer comentários sobre o planejamento pensado manifestando, antecipadamente, a sua opinião a respeito das ações a serem perpetradas. (FORTUNATI, 2007, p. 24)

A publicidade está atrelada a participação, pois inclui a atuação das instâncias de controle social, formalmente constituídas, por força da legislação, para planejar e acompanhar a aplicação dos recursos federais descentralizados a outros entes federados, por meio de fundos.

\section{Contribuições da Lei de Responsabilidade Fiscal (LRF) na Administração dos municípios.}

Os Municípios, tem com autonomia amparada em leis que conferem a capacidade de auto-organização, autogoverno, autoadministração e auto legislação. Municípios organizamse através de Lei Orgânica própria Neste sentido:

A Lei Orgânica do município é um importante instrumento para criação de projetos, assim como o Plano Diretor. O Plano Diretor é uma lei municipal que organiza o crescimento e o funcionamento das cidades, orientando os investimentos a partir de diversos regulamentos das relações urbanas com o objetivo de viabiliza-los igualmente é o Estatuto da Cidade, que reúne instrumentos da política urbana e regulamenta uma série de temas que são essenciais ao município. (GRANJA, 2010, p.24)

Os municípios possuem autonomia e competências administrativas, legislativas e tributárias. O princípio básico da repartição de competências, tanto no âmbito administrativo como no legislativo.

Sendo o município um ente federado compete os assuntos de interesse predominantemente local.

A Lei de Responsabilidade Fiscal (LRF) n ${ }^{\circ}$ 101/2000 que trata das normas finanças dos municípios estabelece as responsabilidades na gestão fiscal dos municípios. 
Segundo a Constituição de 1988A responsabilidade na gestão fiscal pressupõe a ação planejada e transparente, em que se previnem riscos e corrigem desvios capazes de afetar o equilíbrio das contas públicas, mediante o cumprimento de metas de resultados entre receitas e despesas e a obediência a limites e condições no que tange a renúncia de receita, geração de despesas com pessoal, da seguridade social e outras, dívidas consolidada e mobiliária, operações de crédito, inclusive por antecipação de receita, concessão de garantia e inscrição em Restos a Pagar.

Verificamos a importância e contribuição da Lei de Responsabilidade Fiscal (LRF) ao dedicar uma Seção específica à transparência na gestão físcal dentro do Capítulo da Transparência no artigo 48 dizem que o controle e Fiscalização no que se refere à transparência será amplamente divulgados por meios eletrônicos de acesso as todos, sendo certificado mediante incentivo da participação do povo.

Os conceitos de transparência e participação previstos na LRF, referentes à gestão fiscal, foram aprimorados acrescentando à LRF advindos da Lei Complementar n. ${ }^{\circ}$ 131, de 27.5.2009, que delinearam de forma mais precisa a interação entre o cidadão e o setor público, ressaltamos que existe uma estreita relação entre o controle social e a transparência pública.

A LRF tratando da publicidade determina que as informações estejam à disposição podendo ser em portais de transparências. Assim, o cidadão que queira se inteirar de determinadas despesas deverá buscar outras fontes complementares de informações. A exigência da LRF mostra avanços em termos de publicidade na execução do orçamento, mas não sinaliza para os avanços no sentido de evidenciar resultados e efetividade das despesas públicas.

\section{Considerações Finais}

Com este artigo buscou-se analisar e ampliar as várias concepções que se tem sobre o tema partiu do princípio das ideias dos autores que foram citados ao longo de todo trabalho.

Em foco ressaltamos que a inquietação sobre o tema em estudo possibilitou uma visão de como as leis de Responsabilidade Fiscal e a Constituição Federal de 1988 estabelecem metas, diretrizes e dispositivas necessárias para uma gestão eficiente. 
A transparência caracteriza a realidade fiscal dos entes federados. É importante que a administração pública seja transparente, tendo o dever de incluir a participação da sociedade na tomada de decisão, o que estabelece metas específicas e responsabilidades para os gestores.

Promover a participação dos cidadãos, também, é a formação de sujeitos do conhecimento, ativos e envolvidos nas experiências e relações sociais voltadas para a vivencia nas nossas cidades.

As ideias do Constituição Federal, Campos, Dagnino, Fortunar entre outros que estão também relacionadas com o tema contribuíram e vislumbraram quais as principais ações e medidas necessárias para publicidade de informações e atos administrativos, tornar a administração pública democraticamente eficiente.

\section{Referências}

ALMEIDA. Maria Hermínia Tavares de Federalismo e Politicas Sociais. São Paulo: ANPOCS, 1995.

BRASIL. Constituição (1988). Constituição da República Federativa do Brasil. Brasília, DF: Senado Federal: Centro Gráfico.

BRASIL. Lei de Responsabilidade Fiscal: Lei Complementar n. ${ }^{\circ}$ 101. Brasília, DF: Senado Federal. 2000

CAMPOS, Anna Maria. Accountability: Quando poderemos traduzi-la para o português? Revista de Administração Pública, Rio de Janeiro, fev./abr.1990.

DAGNINO. RENATO. et al. Gestão Estratégica da Inovação: Metodologias para analise e implementação. Taubaté: Editora Cabral Universitária 2002.

FERREIRA. AURÉLIO. Dicionário Básico da Língua Portuguesa. Rio de Janeiro: Nova Fronteira, 1999.

GRANJA. SANDRA INÊS BARAGLIO. Elaboração e Avaliação de Projetos.Departamentode Ciências da Administração. Florianópolis. 2010

FORTUNATI. JOSÉ. Gestão da Educação Pública: Caminhos e Desafios. Porto Alegre: Artmed, 2007.

FORTUNATI. JOSÉ. Gestão da Educação Pública: Caminhos e Desafios. Porto Alegre: Artmed, 2007. 
O’DONNEL. GUILHERMO. Sobre o corporativismo e a questão do Estado Cadernos do Departamento de Ciências Politicas, Belo Horizonte, UFMG. 1976.

TRIVINÕS. AUGUSTO NIBALDO SILVA. Introdução à pesquisa em ciências sociais: A pesquisa qualitativa em educação. São Paulo: Atlas. 1987.

\section{Como citar este artigo (Formato ABNT):}

SANTOS, L.M.S.; SILVA, C.M.L. A transparência na Gestão Pública: ferramenta indispensável para participação social. Id on Line Revista Multidisciplinar e de Psicologia, Set-Out de 2016, vol.10, n.31, Supl 2, p. 17-26. ISSN 1981-1179.

Recebido: 23/08/2016

Aceito: 30/08/2016 